\title{
Continuing bonds in adaptation to bereavement: Toward theoretical integration
}

\author{
Margaret Stroebe ${ }^{\mathrm{a}, *}$, Henk Schut ${ }^{\mathrm{a}}$, Kathrin Boerner ${ }^{\mathrm{b}}$ \\ a Department of Clinical \& Health Psychology, Utrecht University, Box 80140, 3508 TC Utrecht, The Netherlands \\ b Brookdale Department of Geriatrics and Palliative Medicine, Mount Sinai School of Medicine/Research Institute on Aging, Jewish Home Lifecare, 120 West 106th Street, New York, \\ NY 10025, USA
}

\section{A R T I C L E I N F O}

\section{Article history:}

Received 19 April 2009

Received in revised form 17 November 2009

Accepted 25 November 2009

\section{Keywords:}

Bereavement

Grief

Attachment

Continuing bonds

Theory

\begin{abstract}
A B S T R A C T
There is lack of clarity in the scientific literature concerning the adaptive functions of continuing versus relinquishing bonds to deceased persons. It remains unclear what type of bonds or underlying processes are related to (mal)adaptive bereavement outcomes. Furthermore, empirical research has rarely been theoretically-driven. Thus, the purpose of this article is to outline a theoretical model for predicting the (mal) adaptiveness of continuing-relinquishing bonds. Attachment theory provides a generic framework for understanding patterns of individual differences in the impact of continuing bonds. Within this framework, using bereavement-specific models compatible with attachment theory, (1) ways of coping with the bond to the deceased can be linked to outcome (using the Dual Process Model, Stroebe \& Schut, 1999), and (2) related cognitions about the deceased person proposed (drawing on Mental Representations Theory, Boerner \& Heckhausen, 2003). This integrative model can be used to systematically examine the relationship between continuing bonds and bereavement adaptation.
\end{abstract}

(c) 2009 Elsevier Ltd. All rights reserved.

\section{Contents}

1. Individual differences in the nature of bonds: the attachment theory perspective . . . . . . . . . . . . . . . . 260

1.1. Attachment styles/dimensions . . . . . . . . . . . . . . . . . . . . . . . . . . . . 260

1.2. Internal working models . . . . . . . . . . . . . . . . . . . . . . . . . . . . . 262

1.3. Affect regulation: hyperactivation and deactivation of the attachment system . . . . . . . . . . . . . . . . . . . 262

2. Differences in grief reactions according to attachment style. . . . . . . . . . . . . . . . . . . . . . . . . . . 262

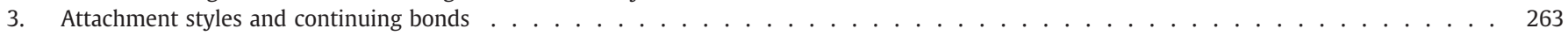

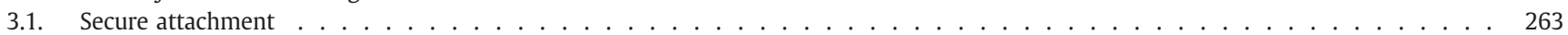

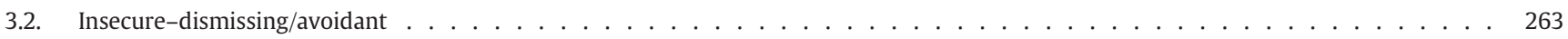

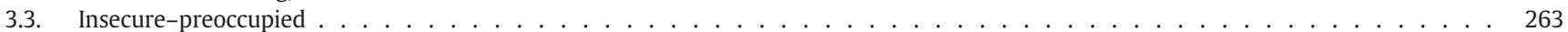

3.4. Insecure-fearful . . . . . . . . . . . . . . . . . . . . . . . . . . . . . . . . 263



5. Cognitive processes in bereavement: Mental Representations Theory . . . . . . . . . . . . . . . . . . . . . . . . . . . . . . . . . . . $\quad$ 264

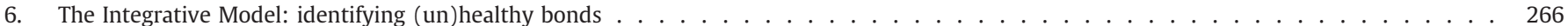

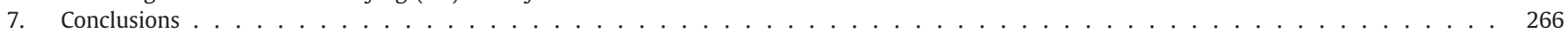

References $\ldots \ldots \ldots$

In their influential volume Continuing Bonds, Klass, Silverman, and Nickman (1996) challenged the long-standing belief deriving from the psychoanalytic tradition (Freud, 1917/1957) that ties to a deceased person need to be relinquished, in order for adaptation to bereavement

\footnotetext{
* Corresponding author. Tel.: +31 30 2533456; fax: +31 302534718.

E-mail addresses: M.S.Stroebe@UU.NL (M. Stroebe), H.Schut@UU.NL (H. Schut), kboerner@jewishhome.org (K. Boerner).
}

to take place. This caused something of a pendulum swing, whereby the focus in the scientific literature came to be placed more on the benefits of continuing a connection with a deceased person. Recently, however, there has been increased understanding that there is no "either/or" rule to be applied: it is neither generally adaptive for bereaved people to continue their bonds with deceased loved ones, nor to relinquish them (e.g., Field, 2008; Field, Gao, \& Paderna, 2005; Stroebe \& Schut, 2005). In line with such reasoning, Field et al. (2005) stressed the role of individual differences in effective versus ineffective use of continuing bonds 
in coping with bereavement (taking "continuing bonds" to mean the presence of an ongoing inner relationship with the deceased person ${ }^{1}$ ). Along similar lines, Stroebe and Schut (2005) argued that researchers need to work toward understanding for whom continuing or relinquishing bonds promote adjustment. For some, it would seem necessary to work toward loosening a bond, for this is retained too closely. For others, precisely the opposite seems to be the case: some persons need to continue or enhance their connection in order to relocate the deceased person in their ongoing lives. Furthermore, Stroebe and Schut (2005) drew attention to the need to examine the process - the underlying dynamics - through which continuing versus relinquishing bonds may be reached, and how these processes are related to adaptation: how do bereaved people go about relocating their loved one - cognitively, behaviorally and affectively - over the course of their bereavement? Accordingly, analysis is needed of both individual differences and underlying processes in continuing/relinquishing bonds.

In general, theoretical formulations should enhance understanding of the complex relationships between continuing/relinquishing bonds and adjustment to bereavement indicated above, enabling more precise predictions about who has beneficial versus detrimental effects from continuing a bond (Field, 2008; Field et al., 2005) and Stroebe, Schut, and Stroebe (2005) adopted an attachment theoretical framework (Bowlby, 1969, 1973, 1980; see also Cassidy \& Shaver, 1999; Mikulincer \& Shaver, 2003, 2008) to explain patterns of individual differences in bereavement reactions. Because bereavement has fundamentally to do with human relationships - not the forming or maintaining, but with the ending of a relationship - it stands to reason that a relationship theory such as attachment theory should be a useful heuristic framework for understanding continuing bonds. Field (2008; see also Field et al., 2005) defined the relationship to the deceased in terms of attachment theory's postulation of separation anxiety and phases of adjustment during bereavement, highlighting the way that continuing bonds may be defined and identifying patterns of continuing bonds according to attachment styles. Along similar lines, Shaver and Tancredy (2001), Mikulincer and Shaver (2008), and Stroebe et al. (2005) related attachment styles to complications in the grieving process. Other theoretical perspectives have focussed on identifying processes in continuing bonds. These perspectives cover a variety of different constructs and potential mechanisms.

Despite availability of the theoretical perspectives mentioned above, empirical research on the relationship between continuingrelinquishing bonds and adjustment has not typically been theorydriven (a rare exception is the empirical study by Field et al., 2005). Furthermore, empirical studies to date have failed to reveal a clear picture about this relationship: sometimes continuing bonds have indeed been found to be associated with better adaptation, sometimes they have not (cf. Boelen, Schut, Stroebe, \& Zijerveld, 2006; Field, GalOz, \& Bonanno, 2003; Schut, Stroebe, Boelen, \& Zijerveld, 2006). Thus, it seems useful to assess available theoretical approaches, with the aim to develop a predictive model for clarifying the relationship between bonds and bereavement outcomes. A central question in this article is: how can the manifestations and patterns of benefits versus detrimental consequences of either holding on to or relinquishing ties to a deceased person be understood on a theoretical level? To address this question, we first outline attachment theory's approach to individual differences, with special reference to the impact of continuingrelinquishing bonds in bereavement. We turn to bereavement-specific models to provide analysis of ways of coping and cognitive processes within this generic theory of attachment, proposing an integrative framework, summarized in Table 1, for predicting and empirically

\footnotetext{
1 For the sake of clarity, we mostly use the term continuing bonds in this manuscript, but on the understanding that the "opposite side of the coin, namely, relinquishing bonds (discontinuing the ongoing relationship with the deceased) is also implicated in predictions.
}

examining the relationship between continuing-relinquishing bonds and adjustment to bereavement.

\section{Individual differences in the nature of bonds: the attachment theory perspective}

As indicated above, attachment theory - with its focus on the nature of relationships between close persons - provides an excellent generic framework for examining the value of continuing versus relinquishing bonds. Thus, we describe this theory in some detail next, in order to draw the links between attachment styles and particular types of continuing-relinquishing bonds.

Early attachment theory described the formation and long-term impact of infants' relationships with their primary caregivers (e.g., Bowlby, 1953; for more detailed reviews of the relationship between attachment patterns and adjustment to bereavement, see Field, 2008; Field et al., 2005; Mikulincer \& Shaver, 2008; Shaver \& Tancredy, 2001; Stroebe et al., 2005). ${ }^{2}$ A basic theme of the theory is that persons who have experienced (lack of) dependability and consequent (in) security in their early childhood relationships will subsequently remain influenced by this in forming, maintaining and - importantly here -relinquishing relationships.

\subsection{Attachment styles/dimensions}

Based on empirical research, attachment theorists developed the well-known classification system of different types of relationships in terms of secure versus insecure attachment styles (e.g., Ainsworth, Blehar, Waters, \& Wall, 1978; Main \& Solomon, 1986, 1990). In brief: Secure attachment in adulthood is characterized by ease in being close to others, feeling comfortable depending on others and, in turn, in having others depend on them. Not surprisingly, secure attachment is associated with more satisfaction and higher levels of psychological well-being than insecure attachment (e.g., Collins \& Read, 1990; Feeney, 1999). Insecure attachments have been classified as dismissing, preoccupied or disorganized. ${ }^{3}$

Adults with a dismissing style are uncomfortable with closeness to others, find it difficult to trust others, to depend on or be dependent on them. Those with a preoccupied style see others as reluctant to get as close to them as they would like and worry about others' love for them or scaring them away with their need for closeness. Finally, relationships that are characterized as disorganized want closeness with others but feel uncomfortable with it and fear rejection. Like those with a dismissing style, they too find it difficult to trust others, but, unlike those with a more dismissing style, they would actually like closer relationships.

More recently - and importantly for understanding the nature of continuing bonds - attachment theorists have come to use continuous variables of attachment-related anxiety and avoidance (i.e. dimensions to do specifically with relationships) instead of the 4 styles, with which they are compatible (see Brennan, Clark, \& Shaver, 1998). Individual differences in attachment style can be measured on these two orthogonal dimensions: A person's position on the anxious

\footnotetext{
${ }^{2}$ Certain points about attachment theory are frequently misunderstood. It is fundamentally a trait-type theory, assuming continuity across the life cycle. In fact, quite some stability has been demonstrated not only across the life span and for different types of relationships such as mother-child and romantic partners (cf. Cassidy \& Shaver, 1999) but even in terms of cross-generation transmission (e.g., Rosenstein \& Horowitz, 1996). Nevertheless, there may be change, for example, the security of attachment (described further on) may be shattered by traumatic separation(s). Second, the borders between the three or four types of attachment are not clearly defined, are flexible and may indeed change not only over time but also between relationships. Persons may also have attachment organization patterns that are more- or less- prototypical of a particular style.

${ }^{3}$ Various labels have been used for the insecure attachment styles. Here we follow those frequently used in the adult attachment and bereavement literatures.
} 
Table 1

Integrative Model of Continuing Bonds and Bereavement Adaptation.

\begin{tabular}{|c|c|c|c|c|c|c|c|}
\hline \multicolumn{2}{|l|}{ Attachment theory } & \multicolumn{3}{|l|}{ Dual Process Model } & \multicolumn{2}{|l|}{ Mental Representation Theory } & \multirow{2}{*}{$\begin{array}{l}\text { Continuing/relinquishing bonds } \\
\text { H. Adaptiveness }\end{array}$} \\
\hline $\begin{array}{l}\text { A. Style \& self/other } \\
\text { representations }\end{array}$ & B. Hyper-/deactivation & C. Orientation & D. Grief reactions & $\begin{array}{l}\text { E. Positive \& negative } \\
\text { appraisal processes }\end{array}$ & F. Control disposition & G. Processes & \\
\hline Secure: Self + Other + & Lo hyper-/lo deactivation & LO \& RO oscillation & Normal grief & $\begin{array}{l}\text { Pos. \& neg. oscillation } \\
\text { LO \& RO }\end{array}$ & $\begin{array}{l}\text { - Balance between primary and } \\
\text { secondary control striving }\end{array}$ & $\begin{array}{l}\text { - Transforms mental tie to } \\
\text { deceased } \\
\text { - Substitution } \\
\text { - Connection \& disengagement }\end{array}$ & CB adaptive: retained but relocated \\
\hline $\begin{array}{l}\text { Insecure-preoccupied: } \\
\text { Self - Other + }\end{array}$ & Hi hyper-/lo deactivation & LO & Chronic grief & Pos. \& mostly neg. LO & - Rigid retention of blocked goal & $\begin{array}{l}\text { - Little transformation } \\
\text { - Little or no substitution } \\
\text { (but idealization, sanctification) } \\
\text { - More connection than } \\
\text { disengagement }\end{array}$ & CB maladaptive: need to loosen \\
\hline $\begin{array}{l}\text { Insecure-dismissing: } \\
\text { Self + Other - }\end{array}$ & Lo hyper-/hi deactivation & RO & $\begin{array}{l}\text { Absent, inhibited } \\
\text { grief }\end{array}$ & Pos. \& neg. RO & $\begin{array}{l}\text {-Excessive secondary control } \\
\text { disposition }\end{array}$ & $\begin{array}{l}\text { - Little transformation } \\
\text { - Devaluation of deceased } \\
\text { - Lo substitution } \\
\text { - More disengagement than } \\
\text { connection }\end{array}$ & $\begin{array}{l}\text { CB relinquished, maladaptive: denial } \\
\text { of bond, need to confront \& continue }\end{array}$ \\
\hline $\begin{array}{l}\text { Insecure-fearful: } \\
\text { Self - Other - }\end{array}$ & Hi hyper-/hi deactivation & $\begin{array}{l}\text { LO \& RO disturbed } \\
\text { oscillation }\end{array}$ & $\begin{array}{l}\text { Complications in } \\
\text { grief assimilating/ } \\
\text { associated with PTSS }\end{array}$ & $\begin{array}{l}\text { Pos. \& mostly neg. } \\
\text { disturbed oscillation } \\
\text { LO \& RO }\end{array}$ & $\begin{array}{l}\text { - Confused control striving } \\
\text { (uncoordinated/imbalanced/ } \\
\text { inconsistent) }\end{array}$ & $\begin{array}{l}\text { - Confusion re. mental tie/ } \\
\text { blocked goal- } \\
\text { - Substitution difficult } \\
\text { - Disturbed process of } \\
\text { connection \& disengagement }\end{array}$ & $\begin{array}{l}\text { CB confusion, maladaptive: need } \\
\text { to confront, continue, find coherence } \\
\text { \& then relocate }\end{array}$ \\
\hline
\end{tabular}

Sellother $-=$ negative representation of self/other.

Self/other $+=$ positive representation of self/other.

$\mathrm{LO}=$ Loss orientation.

$\mathrm{RO}=$ Restoration orien
$\mathrm{CB}=$ Continued bond.

PTSD = Posttraumatic Stress Disorde 
attachment dimension indicates the extent to which the person worries about availability and support of the attachment figure in times of need; that on the avoidant attachment dimension the extent to which he or she distrusts the relationship partner's goodwill and strives to keep independent and distant. Those scoring low on both dimensions are said to be secure, those high on both to be "fearfully avoidant" (Bartholomew \& Horowitz, 1991; Mikulincer \& Shaver, 2008). The dismissing group would score high on avoidance, low on anxiety; the preoccupied high on anxiety and low on avoidance dimensions.

\subsection{Internal working models}

A further basic theme, related to the previous one, is that the child builds implicit working models of relationships between the self and others, which incorporate either predominantly positive or negative representations of the self and others (Bowlby, 1969). These models emerge as basic schemas for viewing the world and they guide future relationships. The attachment patterns described above reflect these working models of self and other (cf. Bartholomew, 1990; Collins \& Read, 1990; Feeney, 1999; Fraley, Waller, \& Brennan, 2000). Bartholomew (1990) argued that models of self and other can be dichotomised as positive (the self is seen as worthy of love and attention; others are seen as available and caring) or negative (the self is seen as unworthy; others are seen as unreliable and rejecting). Put simply, secure persons have positive self and other models, dismissing have positive self, negative other, preoccupied have negative self, positive other, and disorganized have negative self and other models.

It is important to note that these internal working models are more generalized schemas than mental representations of the deceased, which we will describe later on. Internal working models comprise a general set of expectations and/or ways of perceiving and interpreting events that have become gradually internalized and turned into a generalized script (e.g., thinking it is important to help others). As such, they come to constitute a personal, characteristic style (associated with attachment schemas) which affect the way any relationship, separations or losses will be experienced. These models cannot be activated by simple recall or recognition. Table 1, Column A shows these styles and the links with self representation. Column B shows hyper- and deactivation patterns, to be briefly described next.

\subsection{Affect regulation: hyperactivation and deactivation of the attachment system}

When attachment security figures are not available, not only are negative working models formed, but secondary affect regulation strategies come into operation, namely, hyperactivation and deactivation (for details, see Mikulincer, 2008; Mikulincer \& Shaver, 2008). Hyperactivation is characterized by insistent attempts to gain the attention of the attachment figure (e.g., clinging; cognitive and behavioral efforts to establish proximity). Deactivation is characterized by inhibition of proximity-seeking inclinations and behaviors (e.g., suppression of threats; determination to handle stress alone; maintaining distance).

These affect regulation processes are linked to the anxiety and avoidance dimensions described above: A person's position on attachment anxiety shows the extent to which the person worries about other's availability in times of need and reliance on hyperactivating strategies. The person's position on the avoidance dimension indicates the extent of distrust about goodwill and reliance on deactivating strategies for dealing with attachment insecurities.

\section{Differences in grief reactions according to attachment style}

According to Parkes (2001) and Shaver and Tancredy (2001), in general persons with a securely attached style will have normal or healthy grieving. They will react emotionally to the loss of a significant person in their lives, but they will not feel overwhelmed by their grief. As Shaver and Tancredy (2001) described, they would be likely to experience and express their grief to a moderate degree, "more than dismissing individuals but less than preoccupied ones"( p. 80), and they would "be able to provide a coherent account of their loss-related experiences unlike unresolved/disorganized individuals" (p. 80), and access their memories coherently. Persons with a dismissing style would be less likely than the more secure to express much overt emotional upset, would probably avoid crying, and try to suppress and avoid their memories (this suppression being associated with physiological changes, cf. Main, 1996). By contrast, a preoccupied orientation would be associated with high emotionality and expressiveness in grieving, accompanied by an inability to be able to talk or cope constructively with loss (e.g., high levels of rumination). Finally, disorganized attachment orientation is characterized not only by a lack of trust in the self but also in others. Persons with this style may have difficulty in talking coherently about their loss, and show other indications of confusion and poor adaptation to bereavement.

Elsewhere, these patterns have been linked to well-established complications in grief (e.g., Parkes, 2001; Mikulincer \& Shaver, 2008; Shaver \& Tancredy, 2001; Stroebe \& Schut, 1999). Basically, secure attachment (positive self and positive other - who will be notably the deceased, in bereavement) is associated with an uncomplicated course of grieving; dismissive attachment (positive self, negative other) with inhibited, absent grief; preoccupied attachment (negative self, positive other) with chronic (or prolonged, in Prigerson's framework, cf. Prigerson, Vanderwerker, \& Maciejewski, 2008) grief; and disorganized attachment (negative self, negative other) with traumatic variants (possibly symptoms relating to Post Traumatic Stress Disorder). These patterns are summarized in Table 1, Columns A and D.

Empirical evidence has begun to accumulate in support of the above claims (see e.g., Bowlby, 1980; Noppe, 2000; Parkes, 1972/ 1996, 2001, 2006; Shaver \& Tancredy, 2001; Wijngaards-de Meij et al., 2007), although more is needed with respect to the specific associations (e.g., between style of attachment, internal representations of the self and others - including the internal model of the deceased and adjustment). In terms of affect regulation, the loss of an attachment figure signals that proximity seeking is not working and that secondary strategies of hyper- and deactivation need to be adopted. These strategies can be helpful in bereavement, because they provide ways for reorganizing attachment security, which is necessary on the death of an attachment figure. If oscillation between these strategies during bereavement fails to help with restoring a sense of security, continued reliance on them may hinder effective coping or reorganization of working models. According to attachment theory, chronic grieving results from pervasive hyperactivation, whereas absence of grief stems from a defensive deactivation of attachment-related thoughts and actions (Mikulincer, 2008).

While little disagreement has arisen among researchers about the validity of a connection between attachment anxiety and chronic grief (incessant hyperactivation during bereavement would be assumed to be maladaptive), some have doubted the maladaptiveness of avoidance of grief, and questioned whether absent grief really exists (e.g., Bonanno, 2008). From an attachment theory perspective there are good reasons to associate extreme deactivation with pathology. Avoidance has been associated with higher levels of somatic symptoms, suggesting that avoidant defences may block conscious access to distress, which has not been associated with higher distress levels (see Mikulincer, 2008). According to Bowlby (1980), even though such attachment thoughts toward a deceased attachment figure may become dissociated, they continue to influence the bereaved person, causing difficulties in adjustment and physical symptoms.

Since insecure-fearful attachment incorporates tendencies of the other two insecure categories, these persons being intermittently high on both avoidance (deactivation) and anxiety (hyperactivation), 
it would be expected (and there is some empirical support for this) that their bereavement reactions would be characterized by the most disordered forms of grieving, with high levels of anxiety, depression, grief and trauma-related symptoms and alcohol consumption (Fraley \& Bonanno, 2004; Mikulincer, 2008).

\section{Attachment styles and continuing bonds}

In this section, the ways that persons with different attachment orientations deal with their relationship to the deceased person is examined (cf. also Field, 2008; Field et al., 2005): How do persons with different attachment styles continue or relinquish their bonds?

\subsection{Secure attachment}

Following the above analysis, persons with secure attachment styles will be able to retain attachment to a deceased person and to use a continued connection to the deceased to work toward acceptance of loss. In line with the general tendencies to stay close to others emotionally and be comfortable with mutual dependence, one would expect these bereaved people to use the deceased person for guidance, and for solace to be found in reminiscence. Having positive self and other schemas, such persons would be able not only to draw on inner strength, but also to derive comfort and guidance from the deceased. They would be likely to retain their bond on the one hand, but also to gradually let go and relocate the deceased, where relocation implies both withdrawal or loosening, and continuation, in the sense of continued remembrance. These patterns are associated with healthy grieving. Secure person's general mental representations of the self and others (especially the deceased, in this situation) are positive, enabling easier adjustment. Furthermore, secure individuals can use the secondary attachment strategies moderately and usefully with respect to the bond with the deceased, maintaining a symbolic attachment and integrating the lost relationship into internal working models, the deceased can become an "internal source of security rather than a real-world source" (Mikulincer, 2008, p. 35).

\subsection{Insecure-dismissing/avoidant}

In general, maintaining bonds would not be expected to be used and/or to serve such adaptive functions among people in the insecure groups. Dismissing individuals would be likely to deny the need to maintain any tie, trying to remain independent and to keep a distance from thoughts and reminders of the deceased attachment figure. As Field et al. (2005) expressed: “... the avoidant-dismissive individual may fail to revise and integrate his or her schemas of attachment to the new reality of life without the deceased." (p. 289). Attachment avoidance (deactivation) is associated with defensive denial of attachment needs and bonds, persons high on attachment avoidance are unable to maintain useful symbolic bonds with the deceased (Mikulincer, 2008; Mikulincer \& Shaver, 2008).

\subsection{Insecure-preoccupied}

By contrast, the bond is held on to firmly and clingingly by bereaved individuals with a preoccupied orientation. The continued bond to the deceased contrasts with that of the securely attached, in that it encompasses persistent and overriding yearning, longing, and regrets. Here there is less or no gradual move toward relocating the deceased. The bond is held onto rigidly and may tend to dominate and replace all other ongoing relationships. Given the tendency to hyperactivity, insecure-preoccupied persons will tend to be overwhelmed by ruminative thoughts and worries about the deceased and try to maintain an intense attachment to him or her.

\subsection{Insecure-fearful}

Finally, perhaps most complex of all is the nature of bonds to a deceased loved one among those bereaved with fearful, disorganized attachment orientations. As Holmes (2001) described:

"During discussions of loss ..., [the disorganized (fearful)] individual shows striking lapse in the monitoring of reasoning or discourse... [The] individual may lapse into prolonged silence or eulogistic speech." (p. 8)

It is to be expected that these accounts reflect the confused nature of the bond with the deceased person: The bereaved person may oscillate between making efforts to continue and try to use the bond for guidance, or to abandon it and move on. He or she may fail to make sense of the ongoing relationship to the deceased. As noted above, fearfully attached individuals are in a sense caught between the hyper- and deactivating tendencies of the other two insecure styles, leaving them highly confused and with no clear strategy concerning continuing (clinging to) versus relinquishing (detaching from) their bond with the deceased loved one.

In summary, persons with a securely attached orientation would continue bonds to a moderate extent, and gradually relocate the deceased; the dismissive would relinquish their ties to an extreme degree, the preoccupied would continue their bond in a clingy, relentless manner, while the fearful would suffer great confusion and uncertainty in retaining versus relinquishing their tie.

So far we have described individual differences according to the four attachment styles. A remaining question concerns how bereaved people with these different styles go about dealing with the tie to the deceased person, how do they cope? The Dual Process Model of Coping with Bereavement (DPM, Stroebe \& Schut, 1999), to be described next, in a sense "mirrors" the attachment patterns in categorizing ways of coping.

As indicated above, attachment theory also offers insights in terms of the general underlying schemas (working models, mental representations of self and other) associated with attachment styles, but it does not provide detailed analysis of cognitions relating to continuing bonds following the death of a loved one. Following the exploration of coping styles through the DPM, in the subsequent section we describe Boerner and Heckhausen's (2003) analysis in terms of more specific representations of the deceased person, again showing compatibility with the attachment theory framework. Table 1 summarizes how these different components can be combined within a predictive framework.

\section{Ways of coping with bereavement: the Dual Process Model}

Several models within the bereavement field have linked attachment phenomena or (marital) relationship variables to ways of coping (e.g., Bonanno \& Kaltmann, 1999; Parkes, 1988; Rubin, 1992, 1999; Stroebe \& Schut, 1999). Stroebe and Schut's (1999) Dual Process Model (DPM) has the advantage that specific connections with attachment styles, mental representation processes and coping styles can be made. Thus, we restrict consideration to the latter model. The lines of argument in the other models would not, however, seem incompatible with those described below.

Within the framework of the DPM (Stroebe \& Schut, 1999, in press), Stroebe and Schut (2001) analysed the dynamics of coping, attempting to understand how bereaved people are coming to terms with their loss, and how these are regulated across the course of time (see Fig. 1). According to this model, so-called loss-oriented coping has to do directly with the deceased person, while restoration-orientation is focused on secondary stressors that come about as a result of the death (e.g., the change in identity from husband to widower). They posited an oscillation processes whereby the bereaved person would confront 




Fig. 1. The Dual Process Model of Coping with Bereavement Stroebe and Schut (1999).

and avoid the two types of stressors, for example, a bereaved person may be busy thinking about things directly related to the loss, such as going over death events (loss orientation) and may shift to focusing on secondary stressors, such as coping alone with finances (restoration orientation). Following this model, adaptive grieving entails both confrontation and avoidance of the two types of stressor.

The analysis of coping in this model focused on the process of confrontation and avoidance, and on the positive and negative valence of the emotion or situation being confronted or avoided. Thus, emphasis was on the effects of confrontation-avoidance and positive-negative meaning-making as regulatory processes in adaptation. Drawing largely on the empirical studies of Folkman and colleagues (e.g., Folkman, 2001; Folkman, Chesney, Collette, Boccellari, \& Cooke, 1996; Folkman, Chesney, Cooke, Boccellari, \& Collette, 1994), Stroebe and Schut (2001) argued that positive emotions and finding positive meaning are integral to coping well with bereavement, and that these manifestations are not just associated with, but causally related to adaptation. Along similar lines, following the body of research by Nolen-Hoeksema and colleagues (e.g., Nolen-Hoeksema, 2001; NolenHoeksema, Parker, \& Larson, 1994) a ruminative style of coping was identified as leading to persisting grief. Stroebe and Schut (2001) combined these positive and negative appraisal pathways into their DPM model, postulating a regulatory process of oscillation between the two (see Stroebe \& Schut, 1999, 2001). Fig. 2 depicts these processes. Recent research endorses the postulation of such processing: Bonanno, Papa, O'Neill, Westphal, and Coifman (2004) have suggested an explanation for coping with traumatic loss, advocating the need to enhance and suppress emotional expression, that is compatible with the DPM formulation.

Having summarized the basic components of the DPM, we can turn next to coping and continuing bonds. How do persons with different attachment styles go about continuing or relinquishing their bond to a deceased person? It is not difficult to use the DPM constructs outlined above, including the pathways depicted in Fig. 2, to answer this question.

A person with a secure attachment style would oscillate easily between loss and restoration orientation, with positive and negative meaning-making (thoughts and appraisals) within each dimension (e.g., some painful yearning for the deceased but also happy joint memories or relief that $\mathrm{s} / \mathrm{he}$ is suffering no more). Compared with the insecure, there would be more positive, less negative thoughts, which is more conducive to adjustment. The pattern of grief and grieving would follow a non-complicated course, even though suffering and intense grief is to be expected here too, and bonds would be retained in a "healthy" manner, with relocation (i.e., finding a new "place" for him/her in ongoing life) of the deceased occurring over time (for securely attached persons, more than insecure).

The insecure preoccupied attachment style of grieving would be predominantly loss oriented, with such persons suffering - in extreme cases - from chronic grief. The focus would be more loss than restoration focused, and pathways in coping more negative than positive. The bond with the deceased would be clung to. Insecure dismissing persons would be predominantly restoration oriented, with both positive and negative meaning-making focused on these stressors, and suffering in extreme cases from absent, inhibited grief. There would be avoidance of an ongoing bond and denial that the deceased is a significant person in their lives. Insecure fearful attachment is characterized by disturbance of the oscillation process itself (which would occur in a disjointed manner), which fits with the pattern of complications in grief associated with Post Traumatic Stress Disorder. There would be mostly negative, but also perhaps some positive meaning-making, which might be difficult to reconcile or integrate. There would be confusion regarding continuing or relinquishing the bond, and trouble finding coherence with respect to the bond with the deceased person.

\section{Cognitive processes in bereavement: Mental Representations Theory}

Not only is it necessary to understand ways of going about continuing or relinquishing the relationship with the deceased, we also need to understand the nature of mentally-constructed representations of the deceased, and transformations of these during bereavement. Boerner and Heckhausen (2003) developed a framework explicitly to understand such mental representations, providing a specific continuing-relinquishing bonds model. These mental representations are understood to be stored in explicit memory and can be retrieved by a bereaved person for comfort, or sometimes, perhaps, discomfort (e.g., my mother was never helpful, so I will make sure I do things differently). Boerner and Heckhausen (2003) noted 


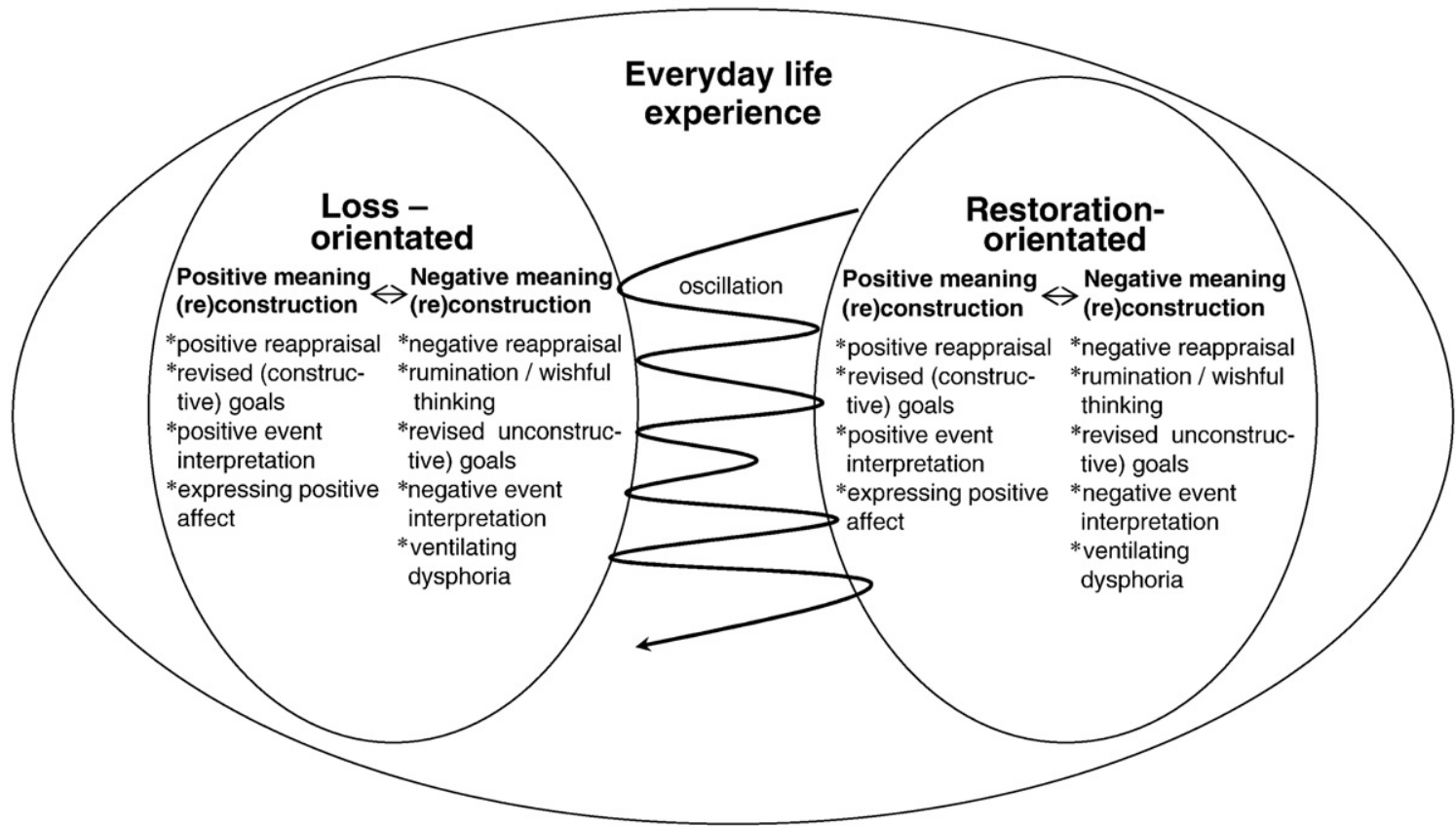

Fig. 2. The Dual Process Model of Coping with Bereavement: Process analysis Stroebe and Schut (2001).

that both explicit representations of the deceased and internalized representations influence the extent and kind of bond to the deceased. Boerner and Heckhausen (2003) proposed that adaptive grieving should be understood as a process of transformation involving both connection and disengagement. The transformation of the relationship, as they described it, involves a deconstruction of certain mentally-constructed components while maintaining or constructing others. Drawing on the evidence that continuing bonds do exist across different life domains, they proposed that a transformation in mental representations occurs through the substitution of the lost relationship with recalled (e.g., remembering what the deceased said) or newly constructed (e.g., imagining what the deceased would say) mental representations of the deceased. They drew on the life-span theory of control (Heckhausen \& Schultz, 1995) to distinguish two fundamental modes of adaptation, primary and secondary control, which reflect goal-engagement and disengagement efforts. Primary control is external environment-oriented and involves attempts to change the world to fit the needs of the individual; secondary control is inward-directed, focused on trying to minimize losses and further primary control. Boerner and Heckhausen (2003) argued that compensatory secondary control strategies, such as disengagement or self-protective attributions, become more adaptive during bereavement than primary control strategies reflecting goal-engagement because the individual is confronted with a situation that is, by its very nature, an irreversible loss of control.

They further postulated that disengagement from a deceased person and accommodation to loss requires cognitive and affective restructuring sub-intentionally, and they also postulated that mechanisms through which disengagement occurs are goal substitution (e.g., by someone similar to the deceased, or by mental representations reflecting certain features of the deceased) and devaluation of the blocked goal. The authors note that in the case of bereavement, a devaluation of the loved one as a person is probably atypical, and would result in disengagement rather than in a transformation involving both disengagement and connection. The latter is more likely when the process is characterized by re- rather than deevaluation (e.g., re-evaluating part of the lost relationship or of aspects of the past joint life).
Inter-individual differences in the use of these processes and strategies were predicted: These authors suggested that the transformation process may be mediated by dispositional coping tendencies and by the social context, which may promote or impair the construction of the mental representations. This offers possibilities to accommodate individual differences, enabling further specification of the dispositional coping tendencies and the impact of social interactions and patterns of disclosure. For example, the disposition to rigidly keep up one's primary control striving, and a social context that discourages memory sharing and thus, is not conducive to recalling or newly developing mental representations of the deceased, are likely to make the transforming of mental ties to the deceased more difficult.

Boerner and Heckhausen's (2003) is, to date, the most finelygrained processing analysis on the topic of continuing-relinquishing bonds, suggesting how the different dynamics might function, and elaborating on the process through which continuing connections may be reached, and be (mal)adaptive. The transformation process is not unlike the oscillation process assumed in the DPM. Thus, in this major respect, there is compatibility between the models.

The mental representation patterns can also be linked to differences between secure versus the insecure attachments, to elucidate their mental images of the deceased and the nature of their continuing bonds (see Table 1 , columns F \& G). One would predict that transforming the mental tie to the deceased would be easier for the securely than for the insecurely attached, in particular, with respect to the process of substitution. Boerner and Heckhausen (2003) described this essentially adaptive process as follows:

“... there is the repeated experience of rewarding attempts to resurrect the lost person in terms of mentally represented legacy components (e.g., what would he have said, how would he have responded). In this way, the original goal of maintaining the relationship with the living person is transformed to the goal of elaborating and enriching those mental representations of the lost person's legacy that carry substitute value. Parts of these mental representations of the lost person's legacy may have existed before and are now activated, modified, or expanded" (p. 219) 
By contrast, attempts to "resurrect" the lost person would be more difficult for the insecurely attached, and substitution of mental representations would be (relatively even more) difficult. For example, in the case of insecure preoccupied persons, substitution would be hampered by idealization or even sanctification (in extreme cases) of the deceased. The worst fears of separation have been realized, it is unlikely that mental representations can easily be transformed. Primary control striving (e.g., desperate attempts to extend the life of the loved one), and hyperactivation as corresponding affect regulation (i.e., insistent attempts to establish proximity to the attachment figure), would stand in the way of the compensatory secondary control processes (e.g., seeking comfort in recollections). For insecure dismissing persons, affect regulation is aimed at maintaining distance from the attachment figure. Thus, transformation through substitution is an unlikely pathway. Instead, processing through devaluation of the deceased person would seem most likely, bringing about disengagement rather than a transformation of the ties to the deceased. This reflects an excessive secondary control orientation, aimed at fending off negative affect at all cost. In the case of insecure fearful persons, the process of substitution would appear most difficult of all. These individuals tend to lack a coherent sense of what they have lost, and it seems that transforming the relationship would be problematic without being able to construct a coherent narrative about the lost person is in the first place. Moreover, the tendency to heavily rely on both hyperactivation and deactivation strategies creates a back and forth movement between insistent proximity seeking and inhibition thereof. This confusion is likely to be also reflected in a person's control striving efforts, undermining the related transformatory processes.

\section{The Integrative Model: identifying (un)healthy bonds}

What are the implications of the identified patterns for adaptation? Is it necessary to impact on or change the nature of the bond with a deceased person?

Persons with a secure style of attachment typically follow an adaptive course of grieving for the lost person. They would not need or benefit from attempts to change the nature of their ongoing relationship to the deceased, because they themselves are likely to transform their bonds to the deceased in an adaptive manner. Boerner and Heckhausen came to similar conclusions (2003):

"The most adaptive pattern of dispositions in control tendencies should be one of balance between primary and secondary control. A balanced disposition would enable the person to maintain ties by using opportunities for transforming the relationship into one carried by mental representations that can serve as substitutes for the actual presence of the loved one." (p.221)

Those with insecure orientations would indeed benefit from changing the nature of their bonds and representations. Given that the insecure preoccupied persons would tend to develop a pattern of holding on to the old ties in a maladaptive manner, they would benefit the most from loosening of the bond, difficult though this may be to achieve. These individuals need to relocate and rebuild their lives more independently of the deceased. Given that models of others are generally extremely positive, while those to do with the self are much more negative, some readjustment of both types of models would be useful (e.g., lowering of idealization of the other). By contrast, insecure dismissing individuals may benefit from greater confrontation with their loss, continuing their bond, and dwelling on the significance of the deceased person in their lives, especially as their mental model of others is generally negative. Finally, insecure fearful persons would probably benefit most by being guided toward confronting and continuing the bond with the deceased person, to enable a coherent understanding of the meaning of the (lost) relationship to emerge. When this is achieved, a gradual withdrawal and relocation could be worked on. Because they have negative models of both self and other, individuals with this orientation may be the most difficult to assist in relocation of the deceased. They may also be particularly prone to having frightening memories.

To summarize (see Table 1 , column $\mathrm{H}$ ), securely attached persons will continue their bond to the deceased in an adaptive manner, it would be retained but relocated over time. This contrasts with all three of the insecure styles: Those with a preoccupied style would need to loosen their bond, which one could characterize as unhealthily "clingy"; those with a dismissing style have relinquished their bond but in a maladaptive manner (likely to appear adaptive at first sight, but actually associated with problems, see Mikulincer, 2008), needing to confront and continue their bonds and learn to relocate them; those with a fearful style have confused patterns of connection with the deceased, incorporating both continuing and relinquishing their bonds: they too are at high risk of negative health consequences, needing to confront, particularly to find coherence, and then relocate their bond.

\section{Conclusions}

In this article we have proposed a new integrative model for understanding the relationship between continued bonds and adaptation to bereavement. We linked attachment theory's categorization of types of relationships with coping orientations in Stroebe and Schut's (1999) DPM, finding remarkable parallels and an easy fit between the theoretical constructs. Likewise, Boerner and Heckhausen's (2003) analysis of mental transformations mirrored the patterns associated with attachment styles, specifically in the context of loss of a loved person. As we noted, these mental representations are not the same as internal working models in the attachment theory sense, but they are compatible with them. In our view, combining these perspectives enables us to understand the nature of continuing bonds and to better understand their relationship to adaptation in bereavement.

Before discussing the implications for research, three points need to be emphasized about the construction and use of such an integrative model. First, in describing associations between attachment styles, internal working models and complications in grief as we have done, and in making connections with coping and cognitive processing in bereavement, there is naturally the risk of over-simplification. In reality, matters are more complicated than we have portrayed them here. For example, persons will not be equally prototypical of any one attachment style or complication of grief, nor will there be "perfect" connections between the variables as postulated here. Nevertheless, in our view, it is important to postulate regularities, not least to try to make sense of the wide variety of ways that persons go about dealing with a lost relationship.

Second, while proposing such associations between processes and adaptation, it also needs to be remembered that they will probably change across the duration of bereavement. For example, negative appraisal may be part of adaptive grieving early on - in contrast with later on - in bereavement.

Third, this article focuses on intrapersonal factors. Yet the context of the loss is clearly also important (cf. Boerner \& Heckhausen, 2003; Bonanno \& Kaltmann's, 1999). For example, if the type of the death was traumatic - even witnessed - this is likely to impact on fundamental beliefs about security and to interact with attachment style in affecting the nature of the ongoing relationship. Likewise, substitution processes may be easier to set in motion if the bereaved individual is surrounded by others grieving the loss (cf. Boerner \& Heckhausen, 2003; Walter, 1996).

Nevertheless, in our view, this integrative perspective can be used as a scientific tool to guide empirical research, hopefully enabling the field to move ahead from the current state of confusion regarding the 
nature and functions of continuing bonds. All of the constructs postulated above can be operationalized and subjected to further empirical scrutiny. For example, one of the first steps would be to empirically examine the connections between attachment styles, ways of coping, and mental representations: It would move the field ahead to investigate the profiles that we outline in Table 1 and the connections between them (e.g., attachment and control disposition, confrontational versus avoidant coping and connection/disengagement processes). A second step would be to relate the profiles to bereavement outcome, as predicted above and in Table 1, thus moving investigation in the direction of prospective, longitudinal studies. The latter type of investigation would test whether our predictions about the relative adaptability of the secure versus insecure attachment styles actually holds up.

Measuring the relevant constructs and dimensions will not be easy (and probably not be possible in a single investigation). Assessment tools are quite advanced in the attachment area, for establishing attachment styles/dimensions (see Mikulincer \& Shaver, 2007). By contrast, measurement of the DPM parameters is comparatively new, although beginnings have been made (as illustrated in a forthcoming Special Issue of the journal Omega, Journal of Death and Dying). Importantly here: Appropriate psychometrically-sophisticated measures of coping have yet to be developed. One suggestion to start with might be to use an adapted version of Nolen-Hoeksema's Ruminative Coping Scale, which could indicate excessive focus on loss orientation (see Nolen-Hoeksema et al., 1994). Guidelines for further DPM-related research have recently been provided by Stroebe and Schut (in press).

Likewise, there is no measure that directly assesses mental representations of the deceased as conceptualized here. However, many - though not all (e.g., the possessions items) - of the items of Field's continuing bonds scale somewhat reflect mental representations (see Field et al., 2003). Furthermore, some items from grief scales that indicate ability to move on with life can represent disengagement (for a review, see Neimeyer, Hogan, \& Laurie, 2008). So long as conceptual overlap is taken care of, grief scales in general such as Prigerson's Prolonged Grief Scale (see Prigerson et al., 2008) and a variety of generic mental and/or physical health measures, can be included to assess the relationships with outcome, to test the outcome predictions for the four different profiles, as summarized in Table 1, Column H.

Ultimately, if the parameters can be well-established empirically, the aim would be for the integrative model to be clinically applicable: it could bring the nature of (maladaptive) bonds to the deceased centre-stage in the planning and provision of support. Already, the role of attachment styles in psychopathology and psychotherapy has been extensively documented (e.g., Mikulincer \& Shaver, 2007). It has been argued that including an understanding of attachment theory facilitates the conceptualization of clients' problems and the selection of appropriate interventions (Shorey \& Snyder, 2006). Hopefully, our framework will contribute to such lines of investigation, specifically for bereaved clients. The model's components could be used to aid identification of those bereaved persons who are at risk of long-term health or adjustment problems. For example, evidence of insecure preoccupied attachment style and rigidity in control striving could be used as indicators for working on the ongoing relationship (e.g., in addition to the application of chronic/prolonged grief criteria). Components of the model could be directly targeted in intervention, for example, work could be done to bring about more balanced appraisals, both with regard to their positive/negative focus, as well as to their loss and restoration focus. Guidance could also be directed toward the reconstruction of mental representations of the deceased person, as well as toward identifying areas where moving on with current life without the deceased can be encouraged. Similarly, the need for balance in control striving could be targeted. In such ways potentially - it should be possible to translate the model's principles into concrete steps for intervention with those who suffer from complicated forms of grief, and to guide them toward more adaptive ways of continuing/relinquishing their bonds with a deceased loved one.

\section{References}

Ainsworth, M. D. S., Blehar, M., Waters, E., \& Wall, S. (1978). Patterns of attachment: A psychological study of the strange situation. Hillsdale, NJ: Erlbaum.

Bartholomew, K. (1990). Avoidance of intimacy: An attachment perspective. Journal of Social and Personal Relationships, 7, 147-178.

Bartholomew, K., \& Horowitz, L. (1991). Attachment styles in young adults: A test of a four-category model. Journal of Personality and Social Psychology, 61, 226-244.

Boelen, P., Schut, H., Stroebe, M., \& Zijerveld, A. (2006). Continuing bonds and grief: A prospective analysis. Death Studies, 30, 767-776.

Boerner, K., \& Heckhausen, J. (2003). To have and have not: Adaptive bereavement by transforming mental ties to the deceased. Death Studies, 27, 199-226.

Bonanno, G. (2008). Grief, trauma and resilience. Grief Matters: The Australian Journal of Grief and Bereavement, 11, 11-17.

Bonanno, G., \& Kaltmann, S. (1999). Toward an integrative perspective on bereavement. Psychological Bulletin, 125, 760-776

Bonanno, G., Papa, A., O'Neill, K., Westphal, M., \& Coifman, K. (2004). The importance of being flexible: The ability to enhance and suppress emotional expression predicts long-term adjustment. Psychological Science, 15, 482-487.

Bowlby, J. (1953). Child care and the growth of love. Harmondsworth: Penguin Books.

Bowlby, J. (1969). Attachment and loss: Vol. 1: Attachment. London: Hogarth/New York: Basic Books.

Bowlby, J. (1973). Attachment and loss: Vol. 2: Separation. London: Hogarth/New York: Basic Books.

Bowlby, J. (1980). Attachment and loss, Volume III: Loss: Sadness and depression. Harmondsworth: Penguin.

Brennan, K., Clark, C., \& Shaver, P. (1998). Self-report measurement of adult attachment: An iintegrative overview. In J. Simpson, \& W. Rholes (Eds.), Attachment theory and close relationships (pp. 46-76). New York: Guilford Press.

Cassidy, J., \& Shaver, P. (Eds.). (1999). Handbook of attachment: Theory, research, and clinical applications New York: Guilford Press.

Collins, N. L., \& Read, S. J. (1990). Adult attachment, working models, and relationship quality in dating couples. Journal of Personality and Social Psychology, 58, 644-663.

Feeney, J. A. (1999). Adult romantic attachment and couple relationships. In J. Cassidy, \& P. R. Shaver (Eds.), Handbook of attachment: Theory, research, and clinical applications (pp. 355-377). New York: Guilford.

Field, N. (2008). Whether to relinquish or maintain a bond with the deceased. In M. Stroebe, R. O. Hansson, H. Schut, \& W. Stroebe (Eds.), Handbook of bereavement research and practice: Advances in theory and intervention (pp. 113-132). Washington: American Psychological Association Press.

Field, N. P., Gal-Oz, E., \& Bonanno, G. (2003). Continuing bonds and adjustment at 5 years after the death of a spouse. Journal of Consulting and Clinical Psychology, 71, $110-117$.

Field, N., Gao, B., \& Paderna, L. (2005). Continuing bonds in bereavement: An attachment theory based perspective. Death Studies, 29, 1-23.

Folkman, S. (2001). Revised coping theory and the process of bereavement. In M. Stroebe, R. O. Hansson, W. Stroebe, \& H. A. W. Schut (Eds.), Handbook of bereavement research: Consequences, coping and care (pp. 563-584). Washington DC: American Psychological Association Press.

Folkman, S., Chesney, M., Collette, L., Boccellari, A., \& Cooke, M. (1996). Postbereavement depressive mood and its pre-bereavement predictors in HIV + and HIV - gay men. Journal of Personality and Social Psychology, 70, 336-348.

Folkman, S., Chesney, M., Cooke, M., Boccellari, A., \& Collette, L. (1994). Caregiver burden in HIV + and HIV- partners of men with AIDS. Journal of Consulting and Clinical Psychology, 62, 746-756.

Fraley, C., \& Bonanno, G. (2004). Attachment and loss: A test of three competing models on the association between attachment-related avoidance and adaptation to bereavement. Personality and Social Psychology Bulletin, 30, 878-890.

Fraley, R. C., Waller, N. G., \& Brennan, K. A. (2000). An item response theory analysis of selfreport measures of adult attachment. Journal of Personality and Social Psychology, 78, $350-365$.

Freud, S. (1917/1957). Mourning and melancholia. In J. Strachey (Ed.), Standard edition of the complete psychological works of Sigmund Freud (pp. 152-170). London: Hogarth Press.

Heckhausen, J., \& Schultz, R. (1995). A life-span theory of control. Psychological Review, $102,284-304$.

Holmes, J. (2001). The search for the secure base: Attachment theory and psychotherapy. Hove, U.K.: Brunner-Routledge.

Klass, D., Silverman, P., \& Nickman, S. (Eds.). (1996). Continuing bonds : New understandings of grief Washington, DC: American Psychological Association Press.

Main, M. (1996). Introduction to the special section on attachment and psychopathology: 2. Overview of the field of attachment. Journal of Consulting and Clinical Psychology, 64, 237-243.

Main, M., \& Solomon, J. (1986). Discovery of a new, insecure-disorganized/disoriented attachment pattern. In T. B. Brazelton, \& M. W. Yogman (Eds.), Affective development in infancy (pp. 95-124). Norwood, NJ: Ablex.

Main, M., \& Solomon, J. (1990). Procedures for identifying infants as disorganized/ disoriented during the Ainsworth Strange Situation. In M. T. Greenberg, D. Cicchetti, \& E. M. Cummings (Eds.), Attachment in the preschool years (pp. 121-160). Chicago: University of Chicago Press. 
Mikulincer, M. (2008). An attachment perspective on disordered grief reactions and the process of grief resolution. Grief Matters: The Australian Journal of Grief and Bereavement, 11, 34-37.

Mikulincer, M., \& Shaver, P. R. (2003). The attachment behavioral system in adulthood: Activation, psychodynamics, and interpersonal processes. In M. P. Zanna (Ed.), Advances in Experimental Social Psychology San Diego: Academic Press.

Mikulincer, M., \& Shaver, P. (2007). Attachment in adulthood: Structure, dynamics, and change. New York: Guilford.

Mikulincer, M., \& Shaver, P. (2008). An attachment theory perspective on bereavement. In M. Stroebe, R. O. Hansson, H. Schut, \& W. Stroebe (Eds.), Handbook of bereavement research and practice: Advances in theory and intervention (pp. 87-112). Washington: American Psychological Association Press.

Neimeyer, N., Hogan, N., \& Laurie, A. (2008). The measurement of grief: Psychometric considerations in the assessment of reactions to bereavement. In M. Stroebe, R. O. Hansson, H. Schut, \& W. Stroebe (Eds.), Handbook of bereavement research and practice: Advances in theory and intervention (pp. 133-161). Washington: American Psychological Association Press.

Nolen-Hoeksema, S. (2001). Ruminative coping and adjustment to bereavement. In M. Stroebe, R. O. Hansson, W. Stroebe, \& H. A. W. Schut (Eds.), Handbook of bereavement research: Consequences, coping and care (pp. 545-562). Washington DC: American Psychological Association Press.

Nolen-Hoeksema, S., Parker, L., \& Larson, J. (1994). Ruminative coping with depressed mood following loss. Journal Pf Personality and Social Psychology, 67, 92-104.

Noppe, I. (2000). Beyond broken bonds and broken hearts: The bonding of theories of attachment and grief. Developmental Review, 20, 514-538.

Parkes, C. M. (1972/1996). Bereavement: Studies of grief in adult life, $1 \mathrm{st} / 3 \mathrm{rd}$ ed London: Routledge.

Parkes, C. M. (1988). Bereavement as a psychosocial transition: Processes of adaptation to change. Journal of Social Issues, 44, 53-65.

Parkes, C. M. (2001). A historical overview of the scientific study of bereavement. In M. Stroebe, R. O. Hansson, W. Stroebe, \& H. A. W. Schut (Eds.), Handbook of bereavement research: Consequences, coping and care (pp. 25-45). Washington DC: American Psychological Association Press.

Parkes, C. M. (2006). Love and loss: The roots of grief and its complications. London: Routledge.
Prigerson, H., Vanderwerker, L., \& Maciejewski, P. (2008). A case for inclusion of prolonged grief disorder in DSM-V. In M. Stroebe, R. O. Hansson, H. Schut, \& W. Stroebe (Eds.), Handbook of bereavement research and practice: Advances in theory and intervention (pp. 165-186). Washington: American Psychological Association Press.

Rosenstein, D., \& Horowitz, H. (1996). Adolescent attachment and psychopathology. Journal of Consulting and Clinical Psychology, 64, 244-253.

Rubin, S. (1992). Adult child loss and the Two-Track Model of Bereavement. Omega: Journal of Death and Dying, 24, 183-202.

Rubin, S. (1999). The Two-Track Model: Overview, retrospect, and prospect. Death Studies, 23, 681-714.

Schut, H., Stroebe, M., Boelen, P., \& Zijerveld, A. (2006). Continuing relationships with the deceased: Disentangling bonds and grief. Death Studies, 30, 757-766.

Shaver, P., \& Tancredy, C. (2001). Emotion, attachment, and bereavement: A conceptual commentary. In M. Stroebe, R. O. Hansson, W. Stroebe, \& H. A. W. Schut (Eds.) Handbook of bereavement research: Consequences, coping and care (pp. 63-88). Washington DC: American Psychological Association Press.

Shorey, H., \& Snyder, C. (2006). The role of adult attachment styles in psychopathology and psychotherapy outcomes. Review of General Psychology, 10, 1-20.

Stroebe, M., \& Schut, H. A. W. (1999). The Dual Process Model of Coping with Bereavement: Rationale and description. Death Studies, 23, 1-28.

Stroebe, M., \& Schut, H. (2001). Meaning making in the Dual Process Model of Coping with Bereavement. In R. A. Neimeyer (Ed.), Meaning reconstruction and the experience of loss (pp. 55-73). Washington: American Psychological Association Press.

Stroebe, M., \& Schut, H. (2005). To continue or relinquish bonds? A review of consequences for the bereaved. Death Studies, 29, 477-494.

Stroebe, M., \& Schut, H. (in press). The Dual Process Model: A decade on. Omega: Journal of Death \& Dying special issue on the Dual Process Model of Coping with Bereavement

Stroebe, M., Schut, H., \& Stroebe, W. (2005). Attachment in coping with bereavement: A theoretical integration. Review of General Psychology, 9, 48-66.

Walter, T. (1996). A new model of grief: Bereavement and biography. Mortality, 1, 7-25

Wijngaards-de Meij, L., Stroebe, M., Schut, H., Stroebe, W., van den Bout, J., van der Heijden, P., et al. (2007). Neuroticism and attachment insecurity as predictors of bereavement outcome. Journal of Research in Personality, 41, 498-505. 